Submitted to J. Phys. Chem. A., 07/25/2006

SUPPORTING MATERIAL

$* * * * * * * * * * * * * * * * * * * * * * * * * * * * * * * * * * * * * * * * * * * * * * * * * * * * * * * * *$

GEOMETRY(C2 symmetry) [B3LYP/6-311++G(d,p) level]:

\begin{tabular}{|c|c|c|c|c|c|}
\hline \multirow{2}{*}{$\begin{array}{l}\text { Center } \\
\text { Number }\end{array}$} & \multirow{2}{*}{$\begin{array}{l}\text { Atomic } \\
\text { Number }\end{array}$} & \multirow{2}{*}{$\begin{array}{l}\text { Atomic } \\
\text { Type }\end{array}$} & \multicolumn{3}{|c|}{ Coordinates (Angstroms) } \\
\hline & & & $\mathrm{X}$ & $\mathrm{Y}$ & $\mathrm{Z}$ \\
\hline 1 & 24 & 0 & 0.000000 & 0.000000 & 0.078517 \\
\hline 2 & 8 & 0 & -1.288170 & 0.035730 & 0.957688 \\
\hline 3 & 8 & 0 & 1.288170 & -0.035730 & 0.957688 \\
\hline 4 & 8 & 0 & 0.000000 & 1.439640 & -0.931652 \\
\hline 5 & 8 & 0 & 0.000000 & -1.439640 & -0.931652 \\
\hline 6 & 1 & 0 & 0.865425 & 1.810739 & -1.150494 \\
\hline 7 & 1 & 0 & -0.865425 & -1.810739 & -1.150494 \\
\hline
\end{tabular}

Rotational constants (GHZ): $4.4146795 \quad 3.9624031 \quad 3.7957944$

Isotopes: Cr-52,O-16,O-16,O-16,O-16,H-1,H-1

\title{
THERMOCHEMICAL DATA
}

(the two internal rotation modes treated as hindered rotors):

Thermodynamic functions:

\begin{tabular}{cccrcc}
$\mathrm{T}$ & $\mathrm{E}$ & $\mathrm{H}$ & \multicolumn{1}{c}{$\mathrm{C}_{\mathrm{p}}$} & $\mathrm{S}$ & $\left(\mathrm{G}^{\circ} \mathrm{T}-\mathrm{H}^{\circ} 298\right) / \mathrm{T}$ \\
$\mathrm{K}$ & $\mathrm{kJ} \mathrm{mol}^{-1}$ & $\mathrm{~kJ} \mathrm{~mol}^{-1}$ & $\mathrm{~J} \mathrm{~mol}^{-1} \mathrm{~K}^{-1}$ & $\mathrm{~J} \mathrm{~mol}^{-1} \mathrm{~K}^{-1}$ & $\mathrm{~J} \mathrm{~mol}^{-1} \mathrm{~K}^{-1}$ \\
298.15 & 106.272345 & 108.751 & 98.0947 & 317.893 & -317.89 \\
300 & 106.437613 & 108.932 & 98.4102 & 318.500 & -317.90 \\
400 & 116.122736 & 119.448 & 112.066 & 348.740 & -322.00 \\
500 & 126.909925 & 131.067 & 120.374 & 374.613 & -329.98 \\
600 & 138.380779 & 143.369 & 125.348 & 396.953 & -339.26 \\
700 & 150.276728 & 156.097 & 128.466 & 416.466 & -348.83 \\
800 & 162.452168 & 169.104 & 130.609 & 433.725 & -358.29 \\
900 & 174.827603 & 182.311 & 132.248 & 449.177 & -367.44 \\
1000 & 187.359520 & 195.674 & 133.619 & 463.163 & -376.24
\end{tabular}

